\section{Trauma do carrinho de supermercado: uma nova modalidade de trauma pediátrico?}

Os lactentes e pré-escolares são freqüentemente transportados nos carros de supermercado acompanhando seus pais, durante as compras. As lesões decorrentes do traumatismo dessa prática são uma importante causa de morbidade pediátrica e mortalidade potencial, sobretudo em crianças menores de 5 anos $^{1,2}$.

Ao realizar uma revisão da literatura sobre essa modalidade de traumatismo, no período dos 10 últimos anos, encontraram-se oito citações ${ }^{3,4}$ de traumatismos pediátricos relacionados a carrinhos de supermercado, sendo somente um artigo em língua latina. No mesmo período, também em revistas pediátricas, indexadas em língua portuguesa, não localizamos citações sobre o tema.

Sosner e colaboradores descreveram, em 1993, uma modificação para ajustar-se aos processos de reabilitação de pacientes portadores de paralisia supranuclear progressiva (PSP). A PSP é infreqüente e caracteriza-se por oftalmoplegia supranuclear, paralisia pseudobulbar e distonia axial, com quedas freqüentes e imprevisíveis. Foi proposto para a reabilitação dos pacientes com PSP um carro de supermercado mais pesado, que poderia evitar o perigo da perda de seu contrapeso, prevenindo quedas freqüentes ${ }^{5}$.

Em 1996, Harrell realizou um estudo com 20 crianças do sexo masculino, de 17 a 22 meses. Observaram-se os efeitos do projeto do carro de supermercado, analisando o comportamento da criança no assento em relação à velocidade. Dois projetos diferentes do carro foram examinados. Independentemente do modelo, conclui-se que dois fatores favoreceriam a ocorrência do traumatismo: (a) incidentes prévios com a criança e (b) a tentativa de escalar para fora do assento do carro nas lojas. Assim, conceituou-se que as diferenças individuais na história da aprendizagem podem determinar o maior risco de uma criança ter ferimento nos carros de supermercado do que as características do projeto do carro ${ }^{6}$.

Estima-se que ocorreram 75.200 traumatismos e lesões relacionadas aos carros de supermercado em crianças menores de 15 anos, atendidas nos serviços de urgência dos EUA, entre 1990 e 1992. Desse total de atendimentos, 2,7\% dos pacientes necessitaram hospitalização. Observou-se também um aumento no número total de lesões, bem como das admissões hospitalares nesse período ${ }^{1}$, sendo que a maior incidência foi em crianças menores de 5 anos, nas quais ocorreram $84 \%$ das lesões e $93 \%$ das hospitaliza- ções ${ }^{1-3}$. Outro dado epidemiológico significativo foi que esses acidentes possuem maior probabilidade de ocorrerem quando o tempo de compra excede a 23 minutos ${ }^{6}$. As lesões mais comuns descritas na literatura são: traumatismo crânio-encefálico (> 75\%); lesões superficiais, como equimoses e escoriações (> 45\%); fraturas ósseas, incluindo as fraturas de crânio (18\%); e lacerações de partes moles $(14 \%)$.

O carrinho de supermercado em seu modelo atual é inapropriado para o transporte de crianças, mesmo utilizando cintos de segurança ${ }^{1,3}$. Acreditamos que o transporte de crianças nos carros de supermercado deveria ser proibido. A prevenção consiste em disponibilizar áreas para que nossos filhos permaneçam sob supervisão, ou mesmo carrinhos individuais, adequados ao transporte seguro das crianças que acompanham seus pais em grandes lojas, mercados ou centros comerciais.

\section{Referências bibliográficas}

1. Smith GA, Dietrich AM, Garcia CT, Shields BJ. Epidemiology of shopping cart - related injuries to children. An analysis of national data for 1990 to 1992. Arch Pediatr Adolesc Med 1995;149:1207-10.

2. Smith GA, Dietrich AM, Garcia CT, Shields BJ. Injuries to children related to shopping carts. Pediatrics 1996; 97:161-5.

3. Casani Martinez C, Morales Suarez-Varela M. Carro de supermercado como causa de hospitalización infantil por accidente. An Esp Pediatr 2001;55: 93-4.

4. Instituto Nacional de Saúde, EUA. PubMed/MEDLINE: http:// www.ncbi.nlm.nih.gov

5. Sosner J, Wall GC, Sznajder J. Progressive supranuclear palsy: clinical presentation and rehabilitation of two patients. Arch Phys Med Rehabil 1993;74: 537-9.

6. Harrell WA. Epidemiology of shopping cart-related injuries to children. Arch Pediatr Adolesc Med 1997;151:105-6.

\section{Dr. Eduardo de Oliveira Duque-Estrada}

Docente de Pediatria da Faculdade de Medicina de Teresópolis e Coordenador do Serviço de Cirurgia Pediátrica Prof. Adilson Castro, do Hospital das Clínicas da Faculdade de Medicina de Teresópolis, RJ

\section{Dr. Jones Ribeiro}

Prof. Titular da Disciplina de Pediatria da Faculdade de Medicina de Teresópolis, Rio de Janeiro 